\title{
Efficiency Evaluation of Postgraduate Education Resource Allocation Based on Overlapping Efficiency Model*
}

\author{
Aixin Wang ${ }^{1}$ \\ Agricultural University of Hebei
}

\author{
Xinglong Liu $^{2}$ \\ Agricultural University of Hebei
}

\author{
Hua $\mathrm{Jin}^{3}$ \\ Agricultural University of Hebei
}

\begin{abstract}
The postgraduate education in China has been promoted by the increasing focus on the talent cultivation and education development. At this stage, however, the efficiency of postgraduate education resources allocation still lingers on a low level in China. In view of the problem, the traditional CCR model was improved and, together with data envelopment analysis (DEA) model and the Lingo software, used to perform regional and cluster analysis on the efficiency of postgraduate education resources allocation. The results show that: the eastern region is the leader in resource allocation efficiency, the overall situation in the central region is better than that in the western region, and the western region is narrowing the gap with the central and eastern regions. Moreover, all the provincial-level administrative regions (hereinafter referred to as provinces) in the Chinese mainland were allocated to five groups, and the province with the highest efficiency in each group was taken as the reference standard for the corresponding group, so that the other provinces in the group could learn from the relevant experience of the reference standard.
\end{abstract}

\section{Keywords}

Overlapping Efficiency Model • Postgraduate Education, Resource Allocation • Clustering Assessment

\footnotetext{
* This work is supported by 2018 The tenth batch of teaching research projects of Hebei Agricultural University (No. 2018YB63)

${ }^{1}$ Correspondence to: Aixin Wang (lecturer), College of Information Science and Technology, Agricultural University of Hebei, Baoding 071000, China. Email: wang-aixin@163.com

${ }^{2}$ College of Information Science and Technology, Agricultural University of Hebei, Baoding 071000, China. Email: lxlhqy@126.com

${ }^{3}$ College of Information Science and Technology, Agricultural University of Hebei, Baoding 071000, China. Email: 3112527@qq.com
}

Citation: Wang, A. X., Liu, X. L., Jin, H. (2018). Research on Efficiency Evaluation of Postgraduate Education Resource Allocation Based on Overlapping Efficiency Model. Educational Sciences: Theory \& Practice, 18(5), 1306-1314. http://dx.doi.org/10.12738/estp.2018.5.029 
Talent cultivation, especially the postgraduate education, directly bears on the long-term development of science and technology in China, and the transformation of China into an innovation-oriented country. With the continuous economic development, there has been a growing emphasis on talent cultivation and education, which greatly boosted the postgraduate education. In 2016, 1.77 million people registered for the Unified National Graduate Entrance Examination, an increase of 7\% over 2015. The growing trend is particularly pronounced in some provincial-level administrative regions (hereinafter referred to as provinces), such as Beijing (6.8\%), Liaoning (11.7\%) and Jiangsu (11.12\%).

The expanding scale of postgraduate education has exacerbated the problem of resource shortage. Currently, the efficiency of postgraduate education resources allocation still lingers on a low level in China, as evidenced by the poor return on investment, and hinders the development of postgraduate education. Therefore, it is possible to improve the efficiency of resource utilization and boost the postgraduate education in China through the efficiency evaluation of postgraduate education resource allocation.

\section{Overlapping Efficiency Model}

The data envelopment analysis (DEA) (Pollin et al., 2008; Du et al., 2014; Tang et al., 2015) has been extensively employed to study the sorting of decision-making units, and given birth to various models (Meshkati et al., 2009; Bennett et al., 2004), including the popular CCR model. However, the CCR model fails to realize the complete sorting of decision-making units based on the efficiency value, and often generates extreme and unrealistic weight coefficient of the efficiency value. Since 1986, many scholars (Cheng et al., 2005; Fang et al., 2013; Fang et al., 2008) have developed a new approach, i.e. the overlapping efficiency evaluation method, that further improves the DEA model based on the CCR model. Through the integration of self-assessment with mutual assessment, the novel method reduces or prevents the evaluation of decision-making units solely by the self-assessment system, making the results more objective. In this way, the two problems facing the CCR model are resolved (Hameed et al., 2016; Giannias and Lekakis,1997).

Assuming that there are $n$ evaluation objects, denoted as $\mathrm{DMU}_{\mathrm{j}}$, where $\mathrm{j}=1, \ldots, \mathrm{n}$, each of which has $\mathrm{m}$ inputs and s outputs (Athanassopoulos and Gounaris, 2001; Zaki and Fapojuwo, 2010), and that the input and output vectors of the $\mathrm{j}$-th DMU are expressed as $\mathrm{x}_{\mathrm{ij}},(\mathrm{i}=\mathrm{I}, \ldots, \mathrm{m})$ and $\mathrm{y}_{\mathrm{r}},(\mathrm{r}=\mathrm{I}, \ldots, \mathrm{s})$, respectively. Then, the relative efficiency value of $\mathrm{DMU}_{\mathrm{d}}$ can be obtained by the CCR model:

$$
\begin{aligned}
& \operatorname{Max} \sum_{r=1}^{s} \mu_{r d} y_{r d}=o_{d}\left(x_{d}, y_{d}\right) \\
& \text { s.t. } \sum_{i=1}^{m} \omega_{i d} x_{i j}-\sum_{r=1}^{s} \mu_{r d} y_{r j} \geq 0, j=1, \ldots, n \\
& \sum_{i=1}^{m} \omega_{i d} x_{i j}=1 \\
& \omega_{i d} \geq 0, i=1,2, \ldots, m
\end{aligned}
$$




$$
\mu_{r d} \geq 0, i=1,2, \ldots, s
$$

where $\omega_{i d}$ and $\mu_{r d}$ are the weights of $x_{i j}$ and $y_{r j}$, respectively. The optimal efficiency value of the DMU $\mathrm{D}_{\mathrm{d}}$ is obtained from the optimal weights $\omega_{1 d}^{*}, \ldots, \omega_{m d}^{*}$ and $\mu_{1 d}^{*}, \ldots, \mu_{s d}^{*}$ is denoted as $\theta_{d}$. Nevertheless, the CCR model faces the following two problems. First, the model does not realize the actual distinction between different DMUs but dividing them into valid and invalid ones (Estrada et al., 2013; Wu et al., 2016); Second, the weight selection might be irrational, for each DMU only seeks to maximize its own efficiency (Fang, 2016).

The problems could be solved by the overlapping efficiency evaluation method. Starting from the optimal weights obtained by the model, it is possible to acquire the overlapping frequency of $\mathrm{DMU}_{\mathrm{j}}(\mathrm{j}=1, \ldots, \mathrm{n})$ relative to $\mathrm{DMU}_{\mathrm{d}}$ :

$$
E_{d j}\left(x_{d}, y_{d}\right)=\frac{\sum_{r=1}^{s} \mu_{r d}^{*} y_{r j}}{\sum_{i=1}^{m} \omega_{i d}^{*} x_{i j}}
$$

where $\mathrm{d}=1, \ldots, \mathrm{n}$.

The average value of $E_{d j}\left(x_{d}, y_{d}\right)$ is:

$$
\overline{E_{j}}\left(x_{d}, y_{d}\right)=\frac{1}{n} \sum_{d=1}^{n} E_{d j}\left(x_{d}, y_{d}\right), d=1, \ldots, n
$$

For each $\operatorname{DUM}_{\mathrm{j}}(\mathrm{j}=1, \ldots, \mathrm{n})$, the average value represents the overlapping efficiency of the $\mathrm{j}$-th decisionmaking unit at the t-th stage (Hatami-Marbini et al., 2014).

In general, the optimal weights $\omega_{1 d}^{*}, \ldots, \omega_{m d}^{*}$ and $\mu_{1 d}^{*}, \ldots, \mu_{s d}^{*}$ are not unique, that is, the value of overlapping efficiency is not unique. In this case, the altruistic strategy and exclusive strategy should be implemented to select one out of the many optimal weights. Following the altruistic strategy, the optimal weight that maximizes the efficiency values of other evaluation units should be selected if there are multiple optimal weights. Hence, the overlapping efficiency value of $\mathrm{DMU}_{\mathrm{j}}$ can be expressed as:

$$
\tilde{E}_{j}\left(x_{d}, y_{d}\right)=\frac{1}{n} \sum_{d=1}^{n} E_{d j}\left(x_{d}, y_{d}\right)
$$

Under the exclusive strategy, the overlapping efficiency value of $\mathrm{DMU}_{\mathrm{j}}$ can be expressed as:

$$
\hat{E}_{j}\left(x_{d}, y_{d}\right)=\frac{1}{n} \sum_{d=1}^{n} \hat{E}_{d j}\left(x_{d}, y_{d}\right)
$$

\section{Data and Indices}

\section{Index selection}

The efficiency of education resource allocation is defined as the output corresponding to the certain education resource investment during the education process. By this definition, the first step to the study on the 
efficiency education resource allocation lies in the determination of various input and output indices. In light of the existing research at home and abroad (Fang et al., 2013; Fang, 2016) and considering the education problems in Chinese universities, the author established an input-output index system for the research (Table 1).

Table 1

Input and output indicators of Graduate Education

\begin{tabular}{ccc}
\hline Category & Metric name (class A) & Metric name (class B) \\
\hline \multirow{2}{*}{ Input indicators } & Human resources(tutor) & Number of persons with senior titles \\
\cline { 2 - 3 } Output & Financial resources (funds) & Research funds \\
\cline { 2 - 3 } indicators & $\begin{array}{c}\text { Personnel training } \\
\text { (postgraduate students) }\end{array}$ & Number of PhD \\
\cline { 2 - 3 } & Scientific research (results) & Number of master \\
\cline { 2 - 3 } & $\begin{array}{c}\text { Social service (transfer of the } \\
\text { achievement) }\end{array}$ & $\begin{array}{c}\text { Number of contracts for technology } \\
\text { transfer }\end{array}$ \\
\hline
\end{tabular}

\section{Data sources}

The research is based on the panel data of China over the past 7 years. The data were extracted from reliable and authentic documents released by government statistics departments, including the Compilation of Science and Technology Statistics in Colleges and Universities, and the Educational Statistics Yearbook of China.

\section{Efficiency Evaluation of Education Resource Allocation}

The efficiency of educational resource allocation in the 31 provinces of the Chinese mainland was analyzed and evaluated by the DEA overlapping efficiency model. The evaluation mainly covers two aspects:

First, regional assessment: the Chinese mainland was divided into three regions (the eastern, central and western regions) based on geographical locations, and the allocation efficiency and efficiency variation were analyzed region by region. Second, clustering assessment: the provinces were clustered into different groups based on the investment scale, and the groups were analyzed and evaluated separately.

\section{Regional assessment}

In view of the drastic difference between different provinces in economic development and education investment, the efficiency of education resource allocation should be analyzed on a regional basis (Table 2).

Through the regional analysis of resource allocation efficiency, it is learned that: the central region generally lags far behind the eastern region but stays ahead of the western region; the interprovincial gap is smaller in the eastern region than that in the central and western regions.

As for the intraregional situation, the leading provinces in the eastern region, namely Fujian, Jiangsu, Shandong and Shanghai, are among the top ten provinces in the country; Hainan, a low-ranked province in the eastern region, ranks the $23^{\text {rd }}$ in the country. The leading provinces in the central region, including Shanxi, Jilin and Hubei, also land in the top ten of the country, but the low-efficiency provinces, e.g. Henan, Hunan, Inner Mongolia and Jiangxi, belong to the bottom ten provinces nationally. The western region features a hug gap 
between different provinces in allocation efficiency; Chongqing is more efficient than any other provinces in China, while Qinghai comes right at the bottom of the national ranking; within the region, Chongqing, Xinjiang and Gansu are doing better than Guizhou, Sichuan, Qinghai and Tibet; the efficiency is particularly poor in Tibet, Ningxia and Qinghai, all of which are ranked near the bottom of the national standing.

Table 2

Universities' resource allocation efficiency in different regions

\begin{tabular}{|c|c|c|c|c|c|}
\hline Region & Province & Efficiency & Ranking & Mean value & Variance \\
\hline \multirow{11}{*}{ the east } & Fujian & 0.953 & 2 & \multirow{11}{*}{0.813} & \multirow{11}{*}{0.008} \\
\hline & Shanghai & 0.908 & 4 & & \\
\hline & Shandong & 0.905 & 5 & & \\
\hline & Jiangsu & 0.855 & 8 & & \\
\hline & Tianjin & 0.821 & 11 & & \\
\hline & Guangdong & 0.813 & 12 & & \\
\hline & Hebei & 0.798 & 14 & & \\
\hline & Zhejiang & 0.77 & 16 & & \\
\hline & Beijing & 0.735 & 18 & & \\
\hline & Liaoning & 0.719 & 19 & & \\
\hline & Hainan & 0.667 & 23 & & \\
\hline \multirow{9}{*}{ the middle } & Hubei & 0.874 & 7 & \multirow{9}{*}{0.724} & \multirow{9}{*}{0.011} \\
\hline & Shanxi & 0.845 & 9 & & \\
\hline & Jilin & 0.822 & 10 & & \\
\hline & Anhui & 0.763 & 17 & & \\
\hline & Heilongjiang & 0.696 & 20 & & \\
\hline & Henan & 0.674 & 22 & & \\
\hline & Neimenggu & 0.65 & 21 & & \\
\hline & Hunan & 0.621 & 25 & & \\
\hline & Jiangxi & 0.568 & 28 & & \\
\hline \multirow{11}{*}{ the west } & Chongqing & 0.982 & 1 & \multirow{11}{*}{0.693} & \multirow{11}{*}{0.041} \\
\hline & Gansu & 0.937 & 3 & & \\
\hline & Xinjiang & 0.879 & 6 & & \\
\hline & Yunnan & 0.805 & 13 & & \\
\hline & Shanxi & 0.781 & 15 & & \\
\hline & Guangxi & 0.693 & 21 & & \\
\hline & Sichuan & 0.618 & 26 & & \\
\hline & Guizhou & 0.583 & 27 & & \\
\hline & Ningxia & 0.517 & 29 & & \\
\hline & Xizang & 0.449 & 30 & & \\
\hline & Qinghai & 0.375 & 31 & & \\
\hline
\end{tabular}

Table 3

Universities' resource allocation efficiency in different regions in the past seven years

\begin{tabular}{cccccccc}
\hline & 1st year & 2nd year & 3rd year & 4th year & 5th year & 6th year & 7th year \\
\hline east & 0.782 & 0.793 & 0.748 & 0.712 & 0.763 & 0.779 & 0.813 \\
\hline middle & 0.701 & 0.611 & 0.633 & 0.591 & 0.711 & 0.71 & 0.724 \\
\hline west & 0.603 & 0.672 & 0.652 & 0.55 & 0.675 & 0.698 & 0.693 \\
\hline
\end{tabular}

Judging by the efficiency variation in the last 7 years (Table 3), the eastern region still maintains an edge over the central and western regions, and continuous to lead in the efficiency of postgraduate education resource allocation. It should be noted that the western region is narrowing the gap with the central and eastern regions. The $2^{\text {nd }}$ year and the $3^{\text {rd }}$ year saw the western region surpassing the central region in allocation efficiency. The possible reasons for the gap bridging include the policy supports (e.g. the "full-scale development program for the western regions") and investment increase thanks to the growing emphasis from all sectors of the society on the higher education in the region. 


\section{Clustering analysis}

After the regional analysis of resource allocation efficiency, it is noticed that the provinces in each region differ greatly on the efficiency of postgraduate education resource allocation. Despite some similarity on economic development, the provinces in the same region invest different levels of resources on education. After all, the education investment is not solely dependent on regional economy or geographic location. In addition, it is impossible to substantially increase the investment scale of postgraduate education resources, such as professors and associate professors. Therefore, the investment scale of postgraduate education should be classified for better analysis of the efficiency of postgraduate education resource allocation in provinces with similar investment scale, especially the identification of a proper reference standard.

With the postgraduate education resource investment as the variable, the clustering analysis was adopted to classify the provinces with similar investment scale into the same region. The classification was completed through two-step clustering: the hierarchical clustering method and the non-hierarchical clustering method. The hierarchical clustering method was employed because it does not require predefinition of how many categories to be clustered. However, the non-hierarchical method was also introduced to make up the defect of the hierarchical clustering method that it does not support backtracking. In short, the number of categories was determined by the hierarchical clustering method, and then the provinces with similar investment scale were assigned to the same group by the non-hierarchical clustering method. The steps are detailed as below:

In Step 1, the hierarchical clustering method was used to classify postgraduate education resource investment in China into different groups. The method maximizes the degree of homogenization within the same group, and ensures the result reliability in small sample analysis. Based on the postgraduate resource investment scale, the 31 provinces were divided into 5 groups (Figure 1):

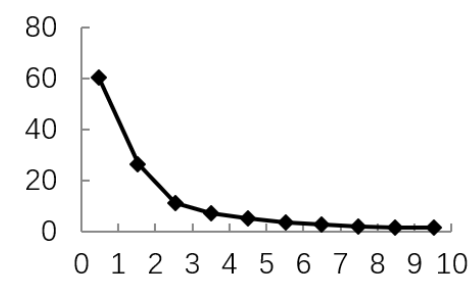

Figure 1. Error coefficient curve based on clustering results

In Step 2, the non-hierarchical clustering method was employed to determine the clustering results in reference to the postgraduate resource investment scale (Table 4):

Table 4

Classification of postgraduate education resource investment scale

\begin{tabular}{cl}
\hline \multicolumn{1}{c}{ Region } & \multicolumn{1}{c}{ Province } \\
\hline No.1 & Beijing \\
\hline No.2 & Shanghai, Zhejiang, Sichuan, Shanxi \\
\hline No.3 & Jiangsu, Hubei \\
\hline No.4 & Hebei, Liaoning, Jilin, Heilongjiang, Anhui, Shandong, Henan, Guangdong \\
\hline \multirow{2}{*}{ No.5 } & $\begin{array}{l}\text { Tianjin, Shanxi, Neimenggu, Gujian, Jiangxi, Guangxi, Hainan, Chongqing, } \\
\text { Guizhou, Yunnan, Xizang, Gansu, Qinghai, Ningxia, Xinjiang }\end{array}$ \\
\hline
\end{tabular}


According to the regional classification results in Table 4, the efficiency values and rankings of the provinces were summed up in recent years (Table 5).

Table 5

Classification of postgraduate education resource investment scale in different regions

\begin{tabular}{|c|c|c|c|}
\hline Region & Province & Efficiency & Ranking \\
\hline No.1 & Beijing & 0.735 & 18 \\
\hline \multirow{4}{*}{ No.2 } & Shanghai & 0.908 & 4 \\
\hline & Shanxi & 0.781 & 15 \\
\hline & Zhejiang & 0.77 & 16 \\
\hline & Sichuan & 0.618 & 26 \\
\hline \multirow{2}{*}{ No.3 } & Hubei & 0.874 & 7 \\
\hline & Jiangsu & 0.855 & 8 \\
\hline \multirow{9}{*}{ No.4 } & Shandong & 0.905 & 5 \\
\hline & Jilin & 0.822 & 10 \\
\hline & Guangdong & 0.813 & 12 \\
\hline & Hebei & 0.789 & 14 \\
\hline & Anhui & 0.763 & 17 \\
\hline & Liaoning & 0.719 & 19 \\
\hline & Heilongjiang & 0.696 & 20 \\
\hline & Henan & 0.674 & 22 \\
\hline & Hunan & 0.621 & 25 \\
\hline \multirow{15}{*}{ No.5 } & Chongqing & 0.982 & 1 \\
\hline & Fujian & 0.953 & 2 \\
\hline & Gansu & 0.937 & 3 \\
\hline & Xinjiang & 0.879 & 6 \\
\hline & Shanxi & 0.845 & 9 \\
\hline & Tianjin & 0.821 & 11 \\
\hline & Yunnan & 0.805 & 13 \\
\hline & Guangxi & 0.693 & 21 \\
\hline & Hainan & 0.667 & 23 \\
\hline & Neimenggu & 0.65 & 24 \\
\hline & Guizhou & 0.583 & 27 \\
\hline & Jiangxi & 0.568 & 28 \\
\hline & Ningxia & 0.517 & 29 \\
\hline & Xizang & 0.449 & 30 \\
\hline & Qinghai & 0.375 & 31 \\
\hline
\end{tabular}

It can be seen from Table 4 that the province with the highest efficiency in each group was taken as the reference standard for the corresponding group. Beijing was listed separately because its education resources were far more concentrated than those in other provinces. In Group 2, Shanghai, as the most efficient province in the group, was taken as the reference standard for other members in the group, including Zhejiang, Shaanxi and Sichuan; the three provinces should draw from the experience of Shanghai to improve their own allocation efficiency. In Group 3, Jiangsu was determined as the reference standard, for it was more efficient than other members in the group. In Group 4, Shandong was selected as the reference standard for Guangdong, Liaoning and other provinces. In Group 5, Chongqing served as the reference standard for provinces like Shanxi, Yunnan and Jiangxi.

In Table 4, the provinces in Groups 1, 2, and 3 were major investors on education, followed by those in Group 4, and those in Group 5 invested the least on education. Some special cases are worth mentioning here. Despite being a major investor, Shanghai is merely the 4th most efficient province. Chongqing, Gansu and Fujian invested less on postgraduate education, but are ranked in the top 3 places in terms of efficiency. The 
low-efficient Tibet, Ningxia and Qinghai were assigned to Group 5. This phenomenon may be attributable to the investment scale. Although major investors are often large producers, it is difficult for the regions with high investment to further expand the output scale in a substantial manner. Therefore, such regions cannot elevate the allocation efficiency. By contrast, the regions with low investment has huge potential for output growth. When the output grows, the allocation efficiency also improves. The efficiency is low in remote regions like Qinghai because such regions are featured by minimal investment scale and output. For instance, Tibet has not yet cultivated a doctoral student.

It should be noted that the scientific research output herein was mainly measured by the number of papers and patents. In some developed provinces, however, many of the resource investment have been transformed into high-end results by universities and colleges. As the output in these provinces is depicted more accurately by quality than quantity, the analysis results of these provinces may deviate from the actual situation.

\section{Conclusion}

After improving the traditional CCR model, this paper evaluates the efficiency of postgraduate education resource allocation in Chinese provinces based on DEA overlapping efficiency model. During the evaluation, the input indices are the number of university professors and associate professors, and research fund; the output indices are number of technology transfers, the number of international papers, the number of patents and the number of doctors and masters.

(1) The regional clustering results show that: the eastern region is the leader in resource allocation efficiency, the overall situation in the central region is better than that in the western region, and the western region is narrowing the gap with the central and eastern regions.

(2) Through the clustering analysis on the investment scale of each province, the provinces were allocated to five groups, and the province with the highest efficiency in each group was taken as the reference standard for the corresponding group, so that the other provinces in the group could learn from the relevant experience of the reference standard.

\section{References}

Athanassopoulos, A., Gounaris, C. (2001). Assessing the technical and allocative efficiency of hospital operations in greece and its resource allocation implications. European Journal of Operational Research, 133(2), 416-431. https://doi.org/10.1016/S0377-2217(00)00180-6

Bennett, A. R., Macphee, S., Betts, R. P. (2004). Resource allocation based on efficiency analysis. Management Science, 50(8), 1134-1144. https://doi.org/10.1287/mnsc.1040.0244

Cheng, Y., Jiang, H., Zhuang, W., Niu, Z., Lin, C. (2005). Efficient resource allocation for china's 3g/4g wireless networks. IEEE Communications Magazine, 43(1), 76-83. https://doi.org/10.1109/MCOM.2005.1381878

Du, J., Cook, W. D., Liang, L., Zhu, J. (2014). Fixed cost and resource allocation based on DEA crossefficiency

European

Journal

of

Operational

Research,

$235(1)$

206-214. 
https://doi.org/10.1016/j.ejor.2013.10.002

Estrada, R., Jarray, A., Otrok, H., Dziong, Z., Barada, H. (2013). Energy-efficient resource-allocation model for ofdma macrocell/femtocell networks. IEEE Transactions on Vehicular Technology, 62(7), 3429-3437. https://doi.org/10.1109/tvt.2013.2253693

Fang, L. (2013). A generalized DEA model for centralized resource allocation. European Journal of Operational Research, 228(2), 405-412. https://doi.org/10.1016/j.ejor.2013.01.049

Fang, L. (2016). Centralized resource allocation DEA models based on revenue efficiency under limited information. Journal of the Operational Research Society, 67(7), 945-952. https://doi.org/10.1057/jors.2015.117

Fang, L., Zhang, C. Q. (2008). Resource allocation based on the DEA model. Journal of the Operational Research Society, 59(8), 1136-1141. https://doi.org/10.1057/palgrave.jors.2602435

Giannias, D. A., Lekakis, J. N. (1997). Policy analysis for an amicable, efficient and sustainable inter-country fresh water resource allocation. Ecological Economics, 21(3), 231-242.

Hameed, A., Khoshkbarforoushha, A., Ranjan, R., Jayaraman, P. P., Kolodziej, J., Balaji, P. (2016). A survey and taxonomy on energy efficient resource allocation techniques for cloud computing systems. Computing, 98(7), 751-774. https://doi.org/10.1007/s00607-014-0407-8

Hatami-Marbini, A., Emrouznejad, A., Agrell, P. J. (2014). Interval data without sign restrictions in DEA. Applied Mathematical Modelling, 38(7-8), 2028-2036. https://doi.org/10.1016/j.apm.2013.10.027

Meshkati, F., Poor, H. V., Schwartz, S. C., Balan, R. V. (2009). Energy-efficient resource allocation in wireless networks with quality-of-service constraints. IEEE Transactions on Communications, 57(11), 3406-3414. https://doi.org/10.1109/TCOMM.2009.11.050638

Pollin, S., Mangharam, R., Bougard, B., Perre, L. V. D., Moerman, I., Rajkumar, R. (2008). Meera: cross-layer methodology for energy efficient resource allocation in wireless networks. IEEE Transactions on Wireless Communications, 7(1), 98-109. https://doi.org/10.1109/TWC.2007.05356

Tang, J., Tay, W. P., Quek, T. Q. S. (2015). Cross-layer resource allocation with elastic service scaling in cloud radio access network. IEEE Transactions on Wireless Communications, 14(9), 5068-5081. https://doi.org/10.1109/TWC.2015.2432023

Wu, J., Chu, J. F., Liang, L. (2016). Target setting and allocation of carbon emissions abatement based on DEA and closest target: an application to 20 apec economies. Natural Hazards, 1-18. https://doi.org/10.1007/s11069-015-1973-6

Zaki, A. N., Fapojuwo, A. O. (2010). Optimal and efficient graph-based resource allocation algorithms for multiservice frame-based ofdma networks. IEEE Transactions on Mobile Computing, 10(8), 1175-1186. https://doi.org/10.1109/TMC.2010.227 